\title{
Effect of Heat Intensity and Duration on the Compressive Strength of Concrete
}

\author{
UKALA, DC \\ Department of Civil Engineering, Delta State University, Abraka, P.M.B. 22, Oleh Campus, Nigeria. \\ E-mail: ukalachuks@gmail.com; ukalacd@delsu.edu.ng;Tel: +2348034260181
}

\begin{abstract}
The objective of this paper is to evaluate the effect of high temperatures and durations on the strength of concrete using concrete specimens produced from two mix ratios of 1:2:4 and 1:3:6 and exposing them to different heat conditions. In the first condition the specimens are subjected to one hour heat intensities of $100^{\circ} \mathrm{C}, 200^{\circ} \mathrm{C}, 300^{\circ} \mathrm{C} \&$ $400^{\circ} \mathrm{C}$ and in the second condition they are subjected to heat periods of $30,60,90$ and 120 minutes under a constant $600^{\circ} \mathrm{C}$ temperature. The 1:2:4 concrete mix specimens lost $85.96 \%$ of its strength after 2 hours of heating at $600^{\circ} \mathrm{C}$ and also lost $16.04 \%$ of its strength after 1 hour duration of $400^{\circ} \mathrm{C}$. The 1:3:6 concrete mix specimens recorded a $73.61 \%$ maximum strength reduction after 2 hours of $600^{\circ} \mathrm{C}$ heat and a $19.63 \%$ strength loss under heat from ambient temperature to $400^{\circ} \mathrm{C}$. Though the results showed an overall reduction in concrete strength it however did not establish a clear cut relationship between concrete strength and heat intensity or heat duration.
\end{abstract}

\section{DOI: https://dx.doi.org/10.4314/jasem.v23i9.5}

Copyright: Copyright $(2019$ Ukala. This is an open access article distributed under the Creative Commons Attribution License (CCL), which permits unrestricted use, distribution, and reproduction in any medium, provided the original work is properly cited.

Dates: Received: 21 May 2019; Revised: 09 September 2019; 12 September 2019

Keywords: Concrete, Compressive strength, Heat Intensity, Heat duration, Fire.

Concrete is a composite material typically made up of aggregates, cement and water. It possesses low thermal conductivity and is non-combustible hence it is generally considered as a fireproof material. Nevertheless when used structurally and reinforced, it is expected to satisfy strength requirement as well as fire resistant requirements. Fire does change or affect some of the properties of concrete and cases such as the fires in the Great Belt Tunnel in Denmark (1994) and the Channel Tunnel linking UK and France (1999) where the concrete used recorded up to $68 \%$ or even $100 \%$ spalling in some parts (Annelies De Wit, 2011) show that fire effect on concrete should not be taken for granted. It is however not so easy to define or model the behavior of concrete exposed to fire because of the complex interaction between the composite materials making up the concrete such as cement gel and aggregate and their individual reactions to thermal exposures (Houry, 2000). The difference in expansion of the cement paste, fine and coarse aggregates individually in the concrete block can lead to cracking and spalling within the concrete which ultimately leads to a reduction in concrete compressive strength. After a fire, any change in the structural properties of concrete caused by changes in the physical and chemical properties of the cement is irreversible (Alarcon-Ruiz, 2005). The uncertainties regarding the effect of heat on concrete members forms part of the reasons for introducing higher safety factors in concrete design than that used in steel design works where knowledge of heat on steel members is largely known (Kuhlmann et al., 2014). Most design codes and methods provide specifications in concrete design based on empirical investigations as there is no model that reflects the true behavior of concrete when exposed to fire (Annelies De Wit, 2011). The stress block used for the structural design of reinforced concrete according to the National Annex of Eurocode 2, part 1-1 (2004) specifies that the maximum acceptable compressive stress of concrete should be $0.85 \mathrm{fck} / 1.5$ (Arya, 2009; Bond, 2005) accounting for a $43.33 \%$ characteristic strength reduction to accommodate for any undesired eventualities such as fire outbreaks where $f_{\text {ck }}$ is the characteristic strength of concrete (Bond, 2005). Criteria for design have been based on results of testing to "standard" fire exposures (ISO, 1975) and are particularly expressed as cover for reinforcement. This is usually as a result of how much heat gets into the concrete and how much the concrete spalls. It however does not directly reflect the changes of the strength of the concrete. EN 1991-1-2, (2002) specifies that only suitable concrete be used in reinforced concrete design. It requires that for a concrete to be suitable, it should have integrity and insulation which is the ability to resist the passage of flames or hot gasses through it and the ability to resist temperature rise on the other side of the member respectively. Satisfying these criteria indicates that the element has the ability to withstand fire but does not imply that the element will or cannot be damaged or 
lose strength as a result of the fire neither does it tell the extent to which the element loses strength during the course of the fire. The size and shape of the concrete cross section is deemed to be principally related to the fire resistant abilities of the member (Arya, 2009) to this effect part 1.2 of Eurocode 2 (2004) suggests minimum cross sectional size values for beams, one way spanning slabs and braced columns as well as the associated axis distances (cover to center of reinforcement) necessary to meet with specific periods of fire resistant. Ghali et al (2015) used ANSYS software in subjecting a model of reinforced concrete to heat of varying intensities and discovered that the concrete withstood temperatures of up to $130^{\circ} \mathrm{C}$. Some other researchers concluded that concrete can withstand up to $400^{\circ} \mathrm{C}$ without any major change in its properties (Bante and Sohoni, 2017). Again just like the European code these works don't disclose how much strength the concrete loses and its implication on the overall safety of the structural element. The objective of this paper is to evaluate the effect of high temperatures and durations on the strength of concrete.

\section{MATERIALS AND METHODS}

Materials: The materials used in this study include fine aggregate (sand), coarse aggregate (granite), cement and water. The fine aggregate used for this study was obtained from Ozoro community in Isoko North Local Government Area of Delta State. The coarse aggregate had a maximum size of $25 \mathrm{~mm}$ which was also obtained from Ozoro community in Isoko North Local Government Area of Delta State. Portland Limestone Cement with fairly high Tricalcium Silicate content was used as the binding material and finally clean water was gotten from the Delta State Polytechnic Ozoro.

Batching and curing method: The concrete specimens were batched by weight for all concrete mix ratios (1:2:4 and 1:3:6). Three concrete cubes made up of mix ratio $1: 2: 4$ were crushed after 28 days curing and used as the reference strength values for other 1:2:4 mixed concrete specimen that were subject to heat of varying intensities and varying times. Outside the control concrete mix, all other specimens were tested for strength after exposures to heat. Three concrete cubes each were crushed after exposure to heat durations of $30,60,90$, and 120 minutes while three concrete cubes each were crushed after exposure to $100^{\circ} \mathrm{C}, \quad 200^{\circ} \mathrm{C}, \quad 300^{\circ} \mathrm{C}$ and $400^{\circ} \mathrm{C}$ elevated temperatures making a total of 27 concrete cubes. This process was repeated for the 1:3:6 concrete mixes. The calculations for batching were carried out according to Sekar (2015) and presented next.

Mass $=$ density $\times$ volume

Density of concrete $=2400 \mathrm{~kg} / \mathrm{m}^{3}$

Volume of one concrete cube $(0.1 * 0.1 * 0.1) \mathrm{m}=0.001 \mathrm{~m}^{3}$

Volume of 27 concrete cubes $(0.001 * 27) \mathrm{m}=0.027 \mathrm{~m}^{3}$

Volume of 27 concrete cubes (including 10\% anticipated weight) $=0.0297 \mathrm{~m}^{3}$

Mass of twenty seven cubes $=2400 \mathrm{~kg} / \mathrm{m}^{3} \times 0.0297 \mathrm{~m}^{3}=71.28 \mathrm{~kg}$.

For 1: $2: 4$ mix ratio with $\frac{\text { water }}{\text { cement }}$ ratio of 0.5 , the sum of mix ratios $=1+2+4+0.5=7.5$

For 1: 3: 6 mix ratio with same $\frac{\text { water }}{\text { cement }}$ ratio, the sum of mix ratios $=1+3+6+0.5=10.5$

The material quantities used for the experiment in weight per group was gotten from the

equation $\frac{1}{\text { sum of mix ratios }} * 71.28 \mathrm{~kg}$ and presented in Table 1

\begin{tabular}{ccc} 
Table 1: Batching by weight of concrete with mix ratios 1:2:4 and & $1: 3: 6$ \\
\hline Materials & Mass (kg) for & Mass (kg) for \\
& $\mathbf{1 : 2 : 4}$ mix ratio & $\mathbf{1 : 3 : 6 ~ m i x ~ r a t i o ~}$ \\
\hline Cement & 9.5 & 6.79 \\
Fine aggregate & 19 & 20.4 \\
Coarse aggregate & 38 & 40.7 \\
Water & 4.75 & 3.4 \\
\hline
\end{tabular}

The concrete cubes of 1:2:4 and 1:3:6 concrete mixes were cast by weight using a $100 \mathrm{~mm} \times 100 \mathrm{~mm} \times$ $100 \mathrm{~mm}$ mould in the lab. A water/cement value of 0.5 was adopted for the mix. The idea behind the use of $1: 2: 4$ and 1:3:6 concretes in the research was to highlight the effect the heat regimes will have on concrete of different strengths knowing that both mixes will produce concrete of different strengths. After mixing, the fresh concrete was placed in the moulds and allowed to harden for a 24 hour period before the concrete cubes were removed from the 
moulds and transferred to the curing tanks where they were cured for 28 days.

Heating methods: Due to the unavailability of a burning furnace and knowing that fire is a chemical reaction that gives up heat and light in varying intensities (Helmenstine \& Marie, 2018), a temperature regulative oven was used to simulate the effect of fire (through heat) on the concrete. After curing, the cubes were removed from the curing tank and surfaced dried. Each test was conducted with three cubes and the average result was reported in this work. After surface drying, three cubes were crushed immediately at ambient temperature (taken as $20^{\circ} \mathrm{C}$ from a temperature gauge in the lab) and the results acted as the reference point for all other subsequent cube strength results subjected to heat.

In getting data pertaining to effects of heat duration on concrete, twelve cube specimens were placed in the oven which was set to a temperature of $600^{\circ} \mathrm{C}$ and after every thirty minutes three cubes were brought out, allowed to cool for about 15 minutes and then crushed. The process was followed until the entire 12 cubes had been removed from the oven, crushed and had their results recorded. After a considerable cooling time, the test targeting the effects of heat intensity on concrete began. Here the oven was regulated to $100^{\circ} \mathrm{C}$ and three cubes were placed in it for a duration of 1 hour. After that the cubes were removed, allowed to cool for 15 minutes and then crushed. The oven was then regulated to $200^{\circ} \mathrm{C}$ and three cubes were placed inside for duration of one hour. At the one hour mark, the cubes were removed from the oven, allowed to cool for 15 minutes and then crushed. This process was repeated for temperatures of $300^{\circ} \mathrm{C}$ and $400^{\circ} \mathrm{C}$. These processes were carried out for both the 1:2:4 and 1:3:6 concrete mixes.

\section{RESULTS AND DISCUSSION}

Figures 1 to 3 show the result of the compressive strength of the entire specimen after heating for varying time intervals.

Heat duration analysis: From figure 1 there appears to be no clear correlation between the compressive strengths of the concrete and the heat durations. Unexpectedly the concrete gained and lost strength at every interval for the concrete made from 1:2:4 and 1:3:6 mixes. The 1:2:4 mixed concrete had an initial strength of $11.92 \mathrm{~N} / \mathrm{mm}^{2}$ as compared to the $10.95 \mathrm{~N} / \mathrm{mm}^{2}$ concrete strength of the 1:3:6 mix indicating the former produced a stronger concrete than the latter. Although there appeared to be a very low correlation between compressive strength and heat durations, there was a general reduction of strength as the duration of heat of the concrete increased. This is represented by the trend line in figure 1 showing that the fire did after all reduce the strength of the concrete generally.

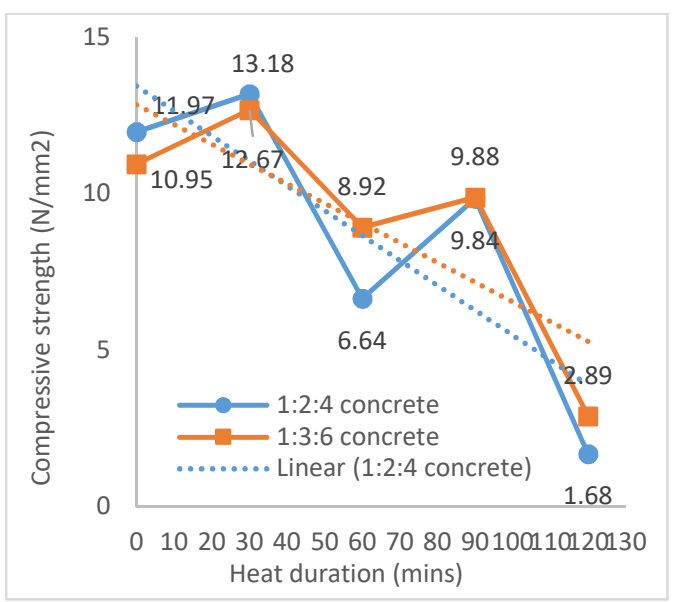

Fig 1: Compressive strength of concrete at different time intervals of heat exposure for both 1:2:4 and 1:3:6 concrete mixes

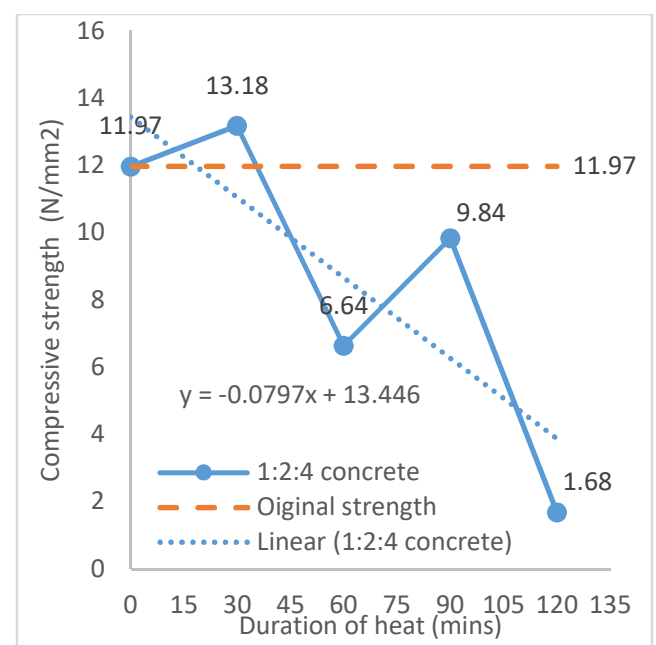

Fig 2: Original and subsequent compressive strengths of 1:2:4 mixed concrete at different time intervals of heat exposure

For the 1:2:4 mix the trendline had a negative slope of approximately 0.8 indicating a general sharp decline of strength as the duration the concrete was exposed to the heat increased (figure 2). However there was an increase in strength at 30 minutes and at 90 minutes of heating in both the 1:2:4 and the 1:3:6 concrete mixes (figure 2 and figure 3 ). The reason for this is not clear but may not be unconnected to free water evaporation from the cement paste or the absorption of moisture from the environment by the specimen at the point of cooling after it had been removed from the furnace and before it was crushed. This phenomena has been reported by Kore \& Vyas (2019), Toumi et al. (2009) and Husem (2006), at $200^{\circ} \mathrm{C}, 800^{\circ} \mathrm{C}$ and $600^{\circ} \mathrm{C}$ respectively. The results also show a relatively high 
deviation in strength of a little above $85 \%$ from the original strength of the concrete to the final strength.

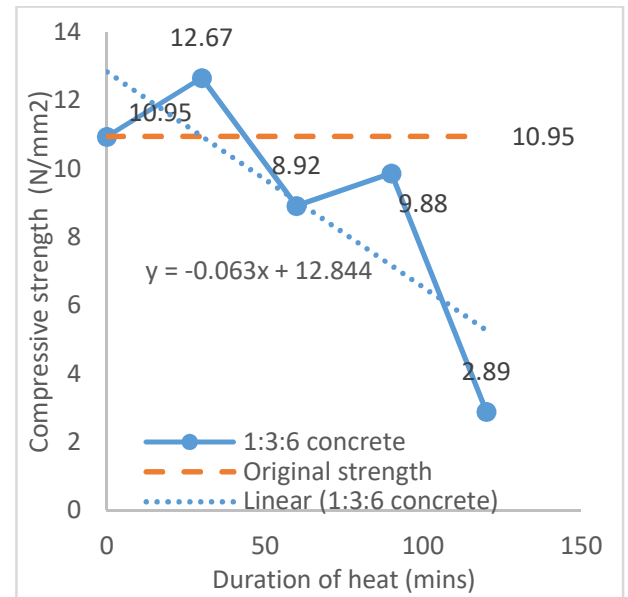

Fig 3: Original and subsequent compressive strengths of 1:3:6 mixed concrete at different time intervals of heat exposure

The results of the 1:3:6 concrete had a negative slope of 0.063 represented by the trendline in figure 3 . This implied the general strength loss was not as drastic as the 1:2:4 concrete having lower strength deviations from the control strength at ambient temperature $\left(10.95 \mathrm{~N} / \mathrm{mm}^{2}\right)$ unlike the 1:2:4 mixed concrete.

Heat intensity analysis: Figures 4 to 6 show the result of the compressive strength of the specimen after being heated at varying heat intensities.

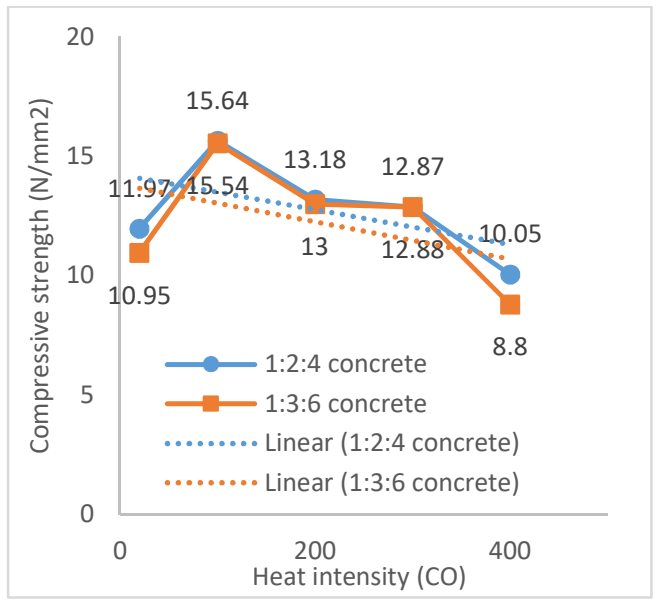

Fig 4: Compressive strength of concrete at different heat intensities for both 1:2:4 and 1:3:6 concrete mixes

The intensity of heat applied to the concrete correlated poorly with the compressive strength of the concrete for both concrete mixes as seen in figure 4 . There was an increase in the strength at $100^{\circ} \mathrm{C}$ from the original strength of the concrete at ambient temperature and after that a gradual decline in strength. The result implies that there will be a gradual decline of strength as the heat intensity increases.

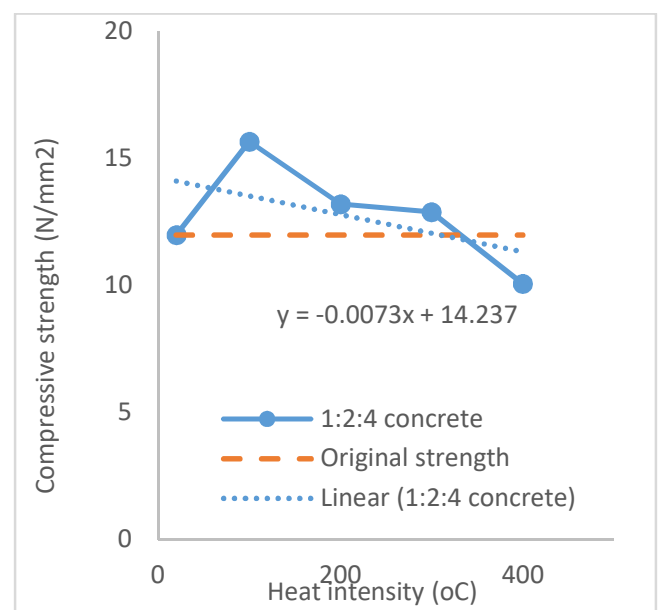

Fig 5: Control compressive strength of 1:2:4 mixed concrete versus subsequent strength values when exposed to different heat intensities

For the 1:2:4 mixed concrete subjected to heat of elevated temperatures, the general strength decline produced a negative slope of 0.0073 (figure 5). The concrete gained strength once at the $100^{\circ} \mathrm{C}$ mark and thereafter recorded a gradual reduction in strength. The strength value only fell short the original concrete strength at about the $340^{\circ} \mathrm{C}$ as it approached $400^{\circ} \mathrm{C}$. Again the reason for this strength gain could be as a result of the reasons previously discussed where the heat causes loss of free water in the cement gel which reduces the water content and invariably increases the strength.

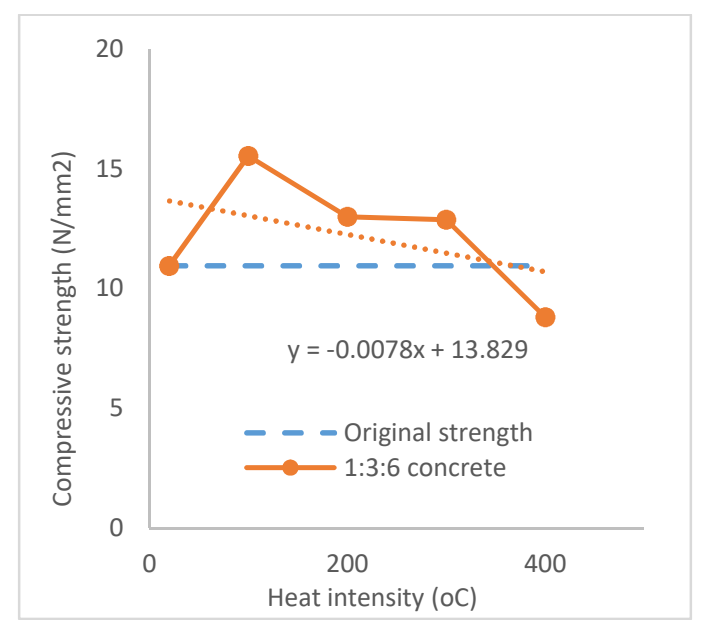

Fig 6: Original compressive strength of 1:3:6 mixed concrete versus subsequent strength values when exposed to different heat intensities

The pattern of strength gain and loss of the 1:3:6 concrete mix follows the same pattern as the 1:2:4 mix and the slopes are similar. In the 1:3:6 concrete mix 
the strength only declined from the original strength around the $350^{\circ} \mathrm{C}$ mark. This shows that at elevated temperatures of up to $350^{\circ} \mathrm{C}$, the concrete will not experience any significant decline in strength. It also shows that the 1:3:6 concrete mix performs slightly better than the 1:2:4 mix when exposed to fire however the difference in performance may not be too significant as the values of strength loss for both mix types were not so high.

Heat conditions and corresponding strength effects analysis: Table 2 tabulates the percentage strength loses of concrete exposed to heat durations and intensities in a manner that makes it easy to compare the overall effects of the application of heat on the concrete specimen.

Table 2: Analysis of heat effects on both 1:2:4 and 1:3:6 mixed concrete samples

\begin{tabular}{|c|c|c|c|c|c|c|c|c|c|}
\hline \multicolumn{5}{|c|}{ Strength comparisons due to heat duration } & \multicolumn{5}{|c|}{ Strength Comparisons due to heat intensity } \\
\hline 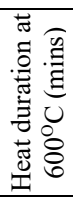 & 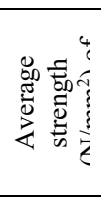 & 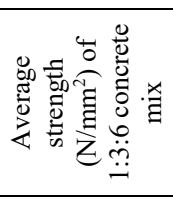 & 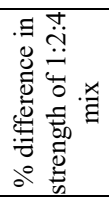 & 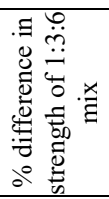 & 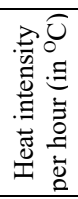 & 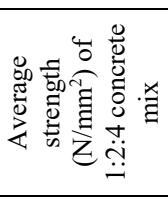 & 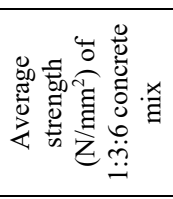 & 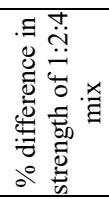 & 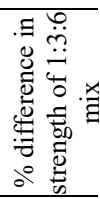 \\
\hline 0 & 11.97 & 10.95 & 0 & 0 & 20 & 11.97 & 10.95 & 0 & 0 \\
\hline 30 & 13.18 & 12.67 & -10.11 & -15.71 & 100 & 15.64 & 15.54 & -30.66 & -41.92 \\
\hline 60 & 6.64 & 8.92 & 44.53 & 18.54 & 200 & 13.18 & 13 & -10.11 & -18.72 \\
\hline 90 & 9.84 & 9.88 & 17.79 & 9.77 & 300 & 12.87 & 12.88 & -7.52 & -17.63 \\
\hline \multirow[t]{2}{*}{120} & 1.68 & 2.89 & 85.96 & 73.61 & 400 & 10.05 & 8.8 & 16.04 & 19.63 \\
\hline & & & $1: 2: 4$ & $1: 3: 6$ & & & & $1: 2: 4$ & $1: 3: 6$ \\
\hline \multicolumn{3}{|c|}{ Avr $\%$ reduction in strength $=$} & 27.64 & 17.24 & \multicolumn{3}{|c|}{ Avr $\%$ reduction in strength $=$} & -6.45 & -11.73 \\
\hline \multicolumn{3}{|c|}{ Max $\%$ loss in strength $=$} & 85.96 & 73.61 & \multicolumn{3}{|c|}{ Max $\%$ loss in strength $=$} & 16.04 & 19.63 \\
\hline \multicolumn{3}{|c|}{ Minimum strength value $=$} & 1.68 & 2.89 & \multicolumn{3}{|c|}{ Minimum strength value $=$} & 10.05 & 8.8 \\
\hline
\end{tabular}

It was observed that between concrete mixes of 1:2:4 and 1:3:6 the concrete exposed to constant temperature but subject to incremental change in the duration of the heat had maximum strength loses of $85.96 \%$ and $73.61 \%$ respectively (Table 2). This amount of strength loss was a lot more than the 16.04 and 19.63 percentage strength loses of concrete made from 1:2:4 and 1:3:6 mixes respectively and subject to different heat intensities for a constant one hour period. This result indicates that the duration of heat on concrete has a greater negative effect on concrete strength than the intensity of the heat. The result also infers that the concrete with less cement to go around the aggregate, that is the 1:3:6 mixed concrete will lose more strength with higher temperatures but lose less strength during a longer heat duration than its 1:2:4 mixed concrete counterpart that has more cement to aggregate volume.

If the concrete is allowed a $43.33 \%$ reduction in characteristic strength during design (refer to introduction), it implies that an hour duration of fire at temperatures up to $400^{\circ} \mathrm{C}$ will not have any serious effects on the concrete since it accounts for a maximum strength loss of $19.63 \%$ only. On the other hand a fire with a temperature intensity of $600^{\circ} \mathrm{C}$ in one hour will completely consume the $43.33 \%$ allowable safety factor of concrete strength and at 2 hours exceed that value by almost 100 percent. This strength reduction could be catastrophic especially where no suitable amount of steel reinforcement is provided.
Conclusion: As the duration and intensity of heat increases on concrete there is a general reduction in strength. This reduction in strength is more pronounced when the specimen is subject to long durations of heat. Stronger concrete reduce in strength more than their weaker counterparts as the duration of the heat increases however the weaker concrete experience a slightly higher reduction in strength than their stronger counterparts when the intensity of the heat increases. A one hour fire producing a temperature of $600^{\circ} \mathrm{C}$ can consume 100 percent of the factor of safety used in the design of already built structures.

\section{REFERENCES}

Alarcon-Ruiz (2005). The use of thermal analysis in assessing the effect of temperature on a cement paste. Cement Concrete Res. 3: 609-613.

Annelies De Wit. (2011). Behavior and structural design of concrete structures exposed to fire. KTH Architechture and Built Environment. Stockholm, Sweden.

Arya, C. (2009). Design of Structural Elements: Concrete, Steelworks, Masonry and Timber Designs to British Standards and Eurocodes. $3^{\text {rd }}$ Ed. Oxon. Taylor and Francis.

Bante, K.S; Sohoni, S.B. (2017) Effect of various temperatures on strength of concrete with partial 
replacement of cement by rice husk ash and partial replacement of coarse aggregate by blast furnace slag. Int. J. Sci. Develop. Res. 2(6) 541550

Bond, A. (2005) Decoding Eurocode 2 + 7: Design of Foundation [Online]. Geocentrix Ltd. Available from:

https://www.scribd.com/document/332811015/ Decoding-Eurocodes-2-and-7 $\quad$ Assessed: $5^{\text {th }}$ December, 2018]

European Committee for Standardization (2004) EN 1992-1-1:2004:E. Eurocode 2: Design of concrete structures - Part 1-1: General rules and rules for buildings. Brussels. European Committee for Standardization

European Committee for Standardization (2004) EN 1992-1-2:2004:E. Eurocode 2: Design of concrete structures - Part 1-2: General rules Structural fire design. Brussels. European Committee for Standardization

Ghali, Y.A; Sugumar, R; Musa, H.A. (2015) Impact of fire on steel reinforcement in reinforced concrete structures. Int. J. Sci. Res. Pub. 5 (10). 1-14.

Helmenstine, A.M. (2018) What Is Fire Made Of? [Online] Thought Co. Available from: https://www.thoughtco.com/what-is-fire-madeof-607313 [Assessed; 30 ${ }^{\text {th }}$ December, 2018]

Husem, M. (2006). The effects of high temperature on compressive and flexural strengths of ordinary and high-performance concrete. Fire Safety J. 41. $155-163$.

International Organization for Standardization (1999) ISO 834-1:1999(E). Fire Resistance Tests Elements of Building Construction - Part 1: General requirements. Switzerland. International Organization for Standardization.

Khoury, G.A. (2000) Effect of fire on concrete and concrete structures. Progress in Struct. Engineering. Mater. 2 (4). p. 429-447

Kore, S.D., \& Vyas, A.K.(2019) Impact of fire on mechanical properties of concrete containing marble waste. J. of King Saud Univ. Engineer. Sci. 31(1). 42-51.

Kuhlmann, U; Wald, F; Hoffman, J; et al. (2014) Design of Steel-to-Concrete Joints Design Manual II. Prague. European Convention for Constructional Steelwork.

Sekar, P.K. (2015) Calculate Cement Sand and Aggregate for Nominal mix concrete in Volume and in Weight [Online]. Civil rnd. Available from: http://civilrnd.com/calculate-cementsand-and-aggregate-for-nominal-mix-concrete/ [Assessed: 3rd January, 2019]

Toumi, B; Resheidat, M; Guemmadi, Z; Chabil, H. (2009) Coupled effect of high temperature and heating time on the residual strength of normal and high strength concretes. Jordan J. Civil Engineer. 3. 322-330. 